\title{
Educação ambiental e as contribuições na gestão dos recursos hídricos
}

Environmental education and the contributions in water resources management

Educación ambiental y las contribuciones en la gestión de los recursos hídricos

Wackson Júnior Teles de Jesus Mestrando em Gestão e Regulação de Recursos Hídricos, UNEMAT, Brasil wacksonjunior@hotmail.com

Solange Aparecida Arrolho da Silva Professora Doutora, UNEMAT, Brasil solarrolho@yahoo.com.br 


\title{
RESUMO
}

O processo de gestão dos recursos hídricos no Brasil têm apresentado diversos desafios, sobretudo na participação social de usuários frente as tomadas de decisão. Diante disso, torna-se necessário buscar medidas para ampliar a participação social dos atores neste processo. Nesse sentido, a educação ambiental surge como uma possibilidade de promover a maior participação dos atores sociais de maneira a conscientiza-los e sensibiliza-los sobre a importância da conservação dos recursos hídricos e da participação dos mesmos no processo de gestão. Desse forma, o presente trabalho tem por objetivo reunir dados e apresentar uma discussão sobre a gestão dos recursos hídricos numa perspectiva da educação ambiental como uma possiblidade de ampliar os processos participativos. A abordagem metodológica utilizada neste estudo foi qualitativa, por meio do método de revisão bibliográfica. A partir educação ambiental pode-se promover a mudança de comportamentos para a consciência ambiental em relação as questões ambientais e recursos hídricos. Nesse sentido, pode-se concluir que a educação ambiental é um mecanismo essencial que possibilita o aumento da participação dos atores na gestão dos recursos hídricos.

PALAVRAS-CHAVE: Gestão dos recursos hídricos. Educação ambiental. Participação social.

\begin{abstract}
The process of management water resources in Brazil has presented several challenges, especially in the social participation of users towards decision-making. Given this, it is necessary to seek measures to increase the social participation of the actors in this process. In this sense, environmental education appears as a possibility to promote greater participation of social actors in a way to raise awareness and awareness of the importance of water resources conservation and their participation in the management process. Thus, this paper aims to gather data and present a discussion on the management of water resources from an environmental education perspective as a possibility to broaden participatory processes. The methodological approach used in this study was qualitative, through the bibliographic review method. From the environmental education one can promote the change of behaviors for environmental awareness regarding environmental issues and water resources. In this sense, it can be concluded that environmental education is an essential mechanism that makes possible the increase of the participation of the actors in the management of water resources.
\end{abstract}

KEY-WORDS: Management of water resources. Environmental education. Social participation.

\section{RESUMEN}

El proceso de gestión de recursos hídricos en Brasil ha presentado varios desafíos, principalmente en la participación social de los usuarios en la toma de decisión. Ante ello, es necesario buscar medidas para aumentar la participación social de los actores en ese proceso. En este sentido, la educación ambiental aparece como una posibilidad de promover una mayor participación de los actores sociales para sensibilizar y concientizar sobre la importancia de la conservación de los recursos hídricos y su participación en el proceso de gestión. Así, este trabajo tiene como objetivo recoger datos y presentar una discusión sobre la gestión de los recursos hídricos a partir de una perspectiva de educación ambiental como posibilidad de ampliar procesos participativos. El enfoque metodológico utilizado en este estudio fue cualitativo, a través del método de revisión bibliográfica. A partir de la educación ambiental se puede promover el cambio de comportamientos para la concientización ambiental en relación a las cuestiones ambientales y recursos hídricos. En este sentido, se puede concluir que la educación ambiental es un mecanismo esencial que posibilita el aumento de la participación de los actores en la gestión de los recursos hídricos.

PALABRAS CLAVE: Gestión de los recursos hídricos. Educación ambiental. Participación social. 


\section{1 - INTRODUÇÃO}

O Brasil tem passado por inúmeras transformações especialmente no campo ambiental. As transformações ambientais no Brasil e no mundo implicaram no surgimento da crise ambiental e hídrica, que têm sido apontadas por vários autores como problemas da modernidade que necessitam maior atenção devido ao esgotamento os recursos naturais.

De acordo com Leff "a crise ambiental é a crise do nosso tempo. O risco ecológico questiona o conhecimento do mundo" (2002, p. 191). Para Tundisi (2008) a crise hídrica é uma questão ambiental ampla que compromete a dinâmica dos ecossistemas e o atendimento dos usos múltiplos da água em quantidade e qualidade.

Levando em consideração o desequilíbrio populacional, ecológico e econômico, garantir sustentabilidade da geração atual nas diversas esferas torna-se cada vez mais complexo. Apesar dos grandes esforços na tentativa de mitigar os problemas que emergiram com a crise hídrica e ambiental, é preciso desenvolver ações que busquem de forma coletiva gerar mudanças de atitudes nos diferentes espaços e promover o maior engajamento da população na luta pelas questões ambientais.

Conforme Leff (2001, p. 179): "os conflitos ecológicos e a crise ambiental não podem ser resolvidos mediante uma administração científica da natureza". Neste sentido, entende-se ser necessário estabelecer ligações entre o conhecimento científico e o conhecimento advindo das relações do homem e natureza.

Segundo Côrtes (2013) os problemas refletem na eficiência de políticas públicas e na conscientização ambiental da população acerca do real valor da água e dos recursos naturais. Neste aspecto, a educação ambiental (EA) é de grande importância na difusão de ações e informações acerca das questões ambientais nos inúmeros espaços.

As abordagens da EA permitem estabelecer um caminho entre as diferentes áreas do conhecimento para configurar projetos transdisciplinares de forma a ampliar os debates e propor medidas que compatibilizem o uso dos recursos hídricos. Para Trevisol (2010) diante da complexidade ambiental, o conhecimento é extremamente importante na construção da autonomia, tanto no sentido de instigar o desenvolvimento de ações e de conscientização da humanidade em relação aos problemas socioambientais.

Conforme Bustos (2003) o processo de gestão dos recursos hídricos, por meio da ação coletiva, tem maior viabilidade e efetividade se tiver como base a educação ambiental, no processo de conscientização e sensibilização da população e governantes para a conservação dos recursos hídricos. Nesta perspectiva, Piccoli et al. (2016) reforçam a importância da educação ambiental como estratégia de mobilização social para o enfrentamento da escassez da água no Brasil.

\section{2 - OBJETIVOS}

Este artigo tem por objetivo reunir dados e apresentar uma discussão sobre a gestão dos recursos hídricos numa perspectiva da educação ambiental como uma possiblidade de ampliar os processos participativos. Espera-se que este trabalho possa contribuir para a compreensão 
da temática e para o desenvolvimento de pesquisas relacionadas a educação ambiental e recursos hídricos.

\section{3 - METODOLOGIA}

A motivação para de realização deste trabalho surgiu a partir de reflexões sobre a educação ambiental e recursos hídricos que foram feitas no IV Seminário de Pedagogia (Araputanga-MT). A abordagem metodológica utilizada na realização deste trabalho foi qualitativa, por meio do método de revisão bibliográfica. Desse modo, para reforçar as discussões, foram consultados artigos, teses e dissertações nacionais referentes a temática.

\section{4 - EDUCAÇÃO AMBIENTAL: BREVE HISTÓRICO}

A educação ambiental em seu contexto histórico resultou de debates acerca das questões ambientais que estavam sendo percebidas pelo mundo todo. Nesse sentido, a educação ambiental surge da interpretação do ambiente e da tentativa de construir modelos de desenvolvimento que proporcionem a relação harmônica entre homem e natureza.

A utilização termo "Educação ambiental" ganhou destaque no meio científico a partir da Conferência de Educação da Universidade de Keele, Grã-Bretanha em 1965, mas foi amplamente difundida somente na Conferência de Estocolmo, em 1972, como um conjunto de estratégias metodológicas e pedagógicas com vislumbre para solução da crise ambiental (TONOZI-REIS, 2004).

De acordo com Carvalho (2002) a educação ambiental ganhou maior visibilidade na década de 80, a partir do avanço dos movimentos socioambientais e do surgimento do pensamento ecologista. Já para Brügger (1999) os debates sobre as questões ambientais iniciaram-se, a partir da década de 1960, embora o surgimento do movimento ecológico tenha ocorrido em 1980.

Contudo, foi somente no ano 1981 que a Educação Ambiental teve amparo legal no Brasil, com a criação da lei no 6.938 de 31 de agosto 1981, que dispõe da Política Nacional do Meio Ambiente (PNMA) e a partir da Conferência das Nações Unidas e Desenvolvimento (Rio-92) e (ECO-92) que o termo ganhou mais força nos debates ambientais. Logo, com a publicação da lei 9.795 de Abril de 1999 foi instituída a Política Nacional de Educação Ambiental que dispõe sobre educação ambiental.

A partir disso pode-se dizer que os profissionais da educação puderam valer-se da educação ambiental nas escolas e nos meios científicos como forma de dialogar sobre a importância dos recursos naturais e sua conservação para as futuras gerações.

\section{5 - EDUCAÇÃO AMBIENTAL E RECURSOS HÍDRICOS}

Considerando a água um bem imprescindível para as futuras e atuais gerações é necessário por meio do processo educativo sensibilizar os atores para as questões ambientais na bacia hidrográfica para conservação dos recursos Hídricos. 
Conforme Carvalho (2008) a proposta educativa de educação ambiental pode auxiliar e contribuir com a formação de sujeitos ecológicos que atuem no ambiente de maneira crítica. Deste modo, entende-se que por meio de projetos de EA pode-se ampliar o processo de participação dos atores nas tomadas de decisões acerca dos recursos hídricos.

Nesse sentido, verifica-se que diante dos problemas ambientais existentes, os projetos de EA são fundamentais para a formação de um sujeito que tome consciência das relações ambientais, para que este seja capaz de assimilar, interpretar e intervir na solução dos problemas de degradação, escassez e qualidade da água.

Conforme Carvalho (2008) a educação ambiental deve estimular o pensamento crítico e inovador do cidadão para promover transformações positivas na sociedade em que o mesmo está inserido.

Guimarães (1995) destaca a educação ambiental como um campo interdisciplinar e transdisciplinar na qual se busca sensibilizar o cidadão para os problemas ambientais e propor soluções por meio de trocas de experiências e elaboração de projetos coletivos.

Conforme o artigo primeiro da lei 9.795/99 que dispõe da Política Nacional de Educação Ambiental (PNEA) entende-se por educação ambiental os processos por meio dos quais o indivíduo e à coletividade constroem valores sociais conhecimentos habilidades atitudes e competências voltadas para a conservação do ambiente bem de uso comum do povo essencial à sadia qualidade de vida e a sua sustentabilidade.

De outro modo, a lei 9.433 de 8 de janeiro de 1997 que dispõe sobre a Política Nacional de Recursos Hídricos (PNRH) tem como fundamento no inciso 1으 a água é um bem de domínio público, logo no inciso 60 a gestão dos recursos hídricos deve ser descentralizada e contar com a participação do poder público e dos usuários e das comunidades.

Desse modo, verifica-se que ambas as leis orientam-se pelo princípio democrático de participação de grupos de pessoas e atores envolvidos com as questões ambientais de forma integrada e participativa na proposição e execução de políticas públicas, em especial dos recursos hídricos.

Neste contexto, é essencial por meio da EA promover no âmbito educativo formal e não formal ações voltadas as questões ambientais de modo a sensibilizar os cidadãos sobre a importância da conservação dos recursos hídricos e da qualidade ambiental.

\section{1- EDUCAÇÃO AMBIENTAL (EA) NA GESTÃO DOS RECURSOS HÍDRICOS}

O processo de gestão dos recursos hídricos no Brasil tem sido um desfaio para os governantes e sociedade civil, pois este processo lança de uma participação integrada, democrática e efetiva de todos os atores, na proposição coletiva de medidas e ações que visem solucionar problemas da crise hídrica e a harmonizar os usos múltiplos da água.

No Brasil, o modelo de Gestão dos recursos hídricos vigente baseia-se no princípio da gestão participativa e descentralizada no âmbito das tomadas de decisões. Para tanto, esse processo de gestão deve ocorrer de maneira sistêmica, justa e equitativa, de modo a atender e compatibilizar o uso da água entre todas as partes interessadas garantindo o equilíbrio social, ambiental e econômico (JACOBI, BARBI, 2007; CAMPOS; FRACALANZA, 2010). 
Entretanto, o processo de gestão encontra alguns impasses em sua efetividade, sobretudo nos conflitos existentes, na participação e organização social dos atores envolvidos, especialmente na sua representatividade.

Nesse contexto, Campos e Francalanza (2010) assinalam ser necessário ampliar os meios de interlocução entre os envolvidos no processo de gestão, e criar estímulos para que os stakeholders assumam maiores responsabilidades na gestão dos recursos hídricos.

Deste modo, Piccoli et al. (2016) destaca a educação ambiental como uma alternativa para estimular e mobilizar para mudança de comportamento acerca da participação e solução dos problemas referentes aos recursos hídricos.

Nesse sentido, a educação ambiental é entendida como o eixo orientador que apresenta possibilidades para a efetividade do processo de gestão, de maneira a integrar e promover a consciência dos atores envolvidos nas tomadas de decisão para a conservação dos recursos hídricos (ALCÂNTARA et al., 2012).

Conforme Campos e Francalanza (2010) a adoção do enfoque integrado na gestão dos recursos hídricos depende da consciência dos atores para os benefícios que eles podem obter com a mesma. Para Tundisi (2008) a participação dos atores no processo de gestão dos recursos hídricos deve melhorar e aprofundar a sustentabilidade da oferta e demanda.

Desse modo, a educação ambiental torna-se relevante para prática de gestão dos recursos hídricos como uma forma de desenvolver a consciência ambiental, sobretudo na forma de interpretar as questões ambientais.

Contudo, para que isso ocorra, Carvalho (2008) assinala que a elaboração os projetos de EA devem ser formulados de forma criteriosa para que o desenvolvimento da prática educativa não perca seu real significado. Conforme Berlinck et al. (2003) a partir da educação ambiental pode-se propor práticas sociais fundamentadas na racionalidade e justiça social que promovam a solução dos conflitos existentes e dos problemas nas formas de relacionamento da população com os recursos hídricos coletivamente.

Para Lima (1999) o modo dialógico da educação ambiental constitui um recurso contra a ausência de participação, e a indiferença comuns em propostas educativas. Ainda conforme Lima (1999) isto porque a dimensão do processo educativo considera a influência de todos os aspectos social, ambiental, econômico, cultural e político.

Desta maneira, a participação da comunidade é imprescindível nas práticas da Educação Ambiental. Faz-se necessário a participação coletiva e a representatividade de diferentes valores, percepções e hábitos, para que a comunidade compreenda de forma clara e objetiva a importância das práticas de educação, buscando uma visão socioeducativa e política.

De outro modo, Berlinck et al. (2016) aponta que no campo da educação ambiental as soluções estruturais e comportamentais são meios de resolver dilemas sociais, possibilitando a solução de conflitos e permitindo a maior cooperação dos envolvidos no processo de gestão (Figura 1). 
FIGURA 1 - Integração de soluções estruturais e comportamentais em decisões sobre usos de recursos com apoio da Educação Ambiental.

Fonte: BERLINCK et al. 2003.

Diante da problemática de escassez hídrica, o aumento do consumo de água faz com que seja

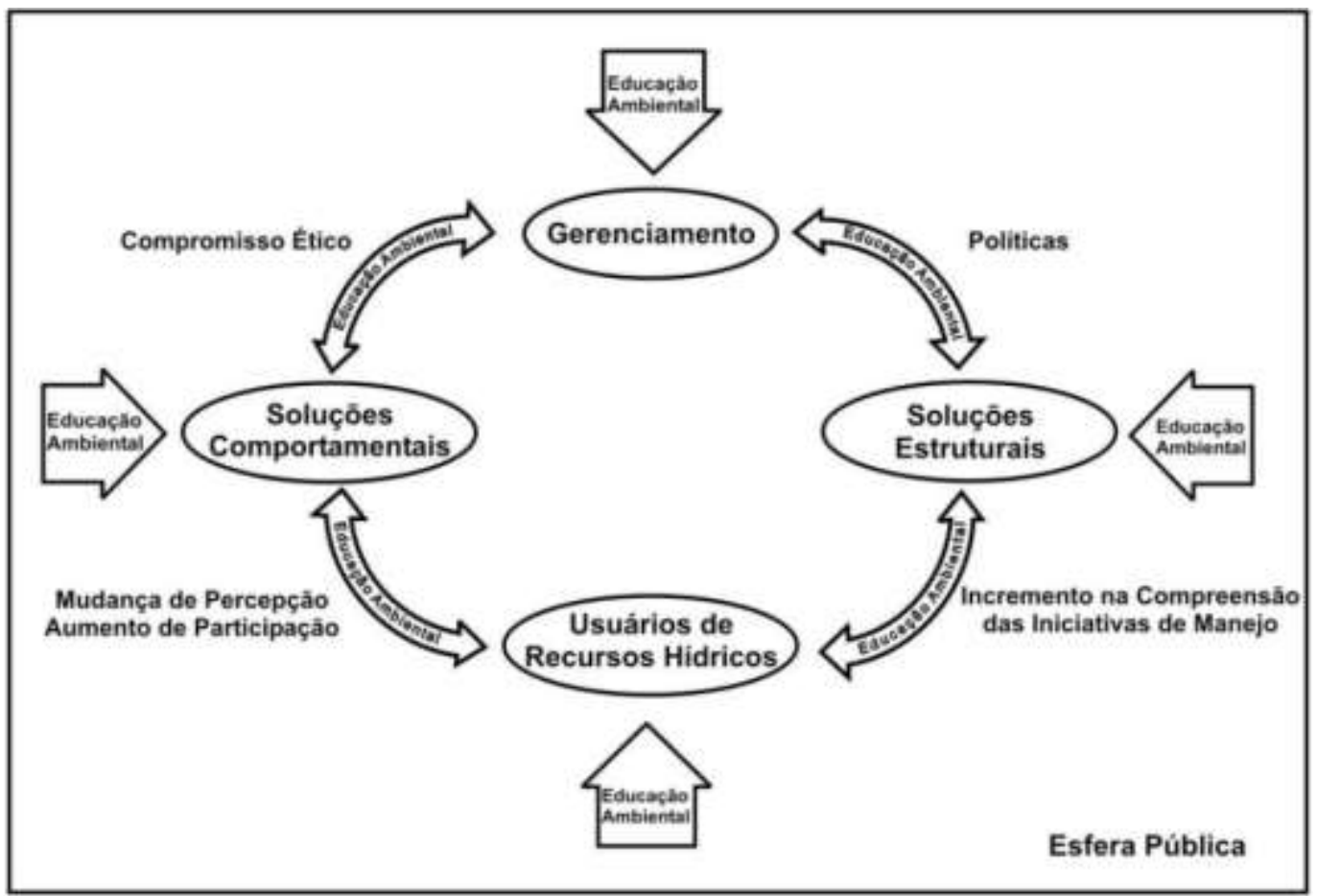

necessária a ampliação de estratégias, técnicas e práticas de educação ambiental voltada para o desenvolvimento sustentável com caráter de fomentar a participação social e reforçar os debates sobre a importância de conservar os recursos hídricos nas diferentes esferas.

Assim, com a conscientização e sensibilização dos atores sociais, por meio da EA, espera-se estimular a mudança de comportamento para promover a maior participação acerca da gestão dos recursos hídricos. De acordo com Loureiro (2006) a participação social permite estabelecer relações educação-ambiente para buscar alternativas frente aos problemas socioambientais.

Segundo Oliveira (2008) a educação ambiental atua como campo de ação pedagógica para capacitação e conscientização das pessoas na intervenção e transformação da realidade local por meio da participação social.

Da mesma forma como a água é de usos múltiplos, a educação ambiental possui um caráter multidisciplinar que permite a integração e melhora qualidade de vida, proporcionando uma visão do todo e a predição de eventos críticos e o desenvolvimento sustentável. Nesse aspecto, a água é um "elemento natural de ligação de todas as coisas, capaz de fazer dialogar áreas do conhecimento tão diferentes como filosofia, física e ecologia". (BARBOSA; BARRETO, 2008, p. 12).

Devido à grande demanda da água nos múltiplos setores é importante que todo processo de gestão seja desenvolvido de maneira integrada entre todas as áreas de conhecimento para que os anseios dos interessados possam ser atendidos. 


\section{6 - CONSIDERAÇÕES FINAIS}

Diante do exposto, educação ambiental proporciona conscientizar e sensibilizar os atores acerca da importância de conservação dos recursos hídricos, sendo assim, é de fundamental importância para estimular a participação social e melhorar a articulação dos interessados no processo de gestão.

Tendo em vista, as múltiplas abordagens da educação ambiental diante dos problemas relacionados aos recursos naturais, a EA pode ser entendida como um mecanismo essencial para rever os valores e atitudes relacionados às questões ambientais.

Nesse sentido, mediante o desenvolvimento de projetos educativos no âmbito formal e não formal a EA apresenta-se como uma possibilidade de ampliar as discussões e estimular a sociedade civil a atuar de maneira participativa no processo de gestão dos recursos hídricos.

\section{AGRADECIMENTO}

O presente trabalho foi realizado com apoio da Coordenação de Aperfeiçoamento de Pessoal Nível Superior - Brasil (CAPES) - Código de Financiamento 001, agradeço também ao Programa de Mestrado Profissional em Rede Nacional em Gestão e Regulação de Recursos Hídricos ProfÁgua, Projeto CAPES/ANA AUXPE №. 2717/2015, pelo apoio técnico científico aportado até o momento.

\section{REFERÊNCIAS BIBLIOGRÁFICAS}

ALCÂNTARA, L. A.; SILVA, M. C. A.; ARAÚJO, R. K.; NISHIJIMA, T. Práticas de Educação Ambiental na Gestão de Recursos Hídricos. Revista Eletrônica em Gestão, Educação e Tecnologia Ambiental, 5(5), 741-748, 2012.

BARBOSA, F.; BARRETO, F. C. Diferentes visões da água. Ângulos da água: desafios da integração. Belo Horizonte: Editora UFMG, p. 11-24, 2008.

BERLINCK, C. N.; CALDAS, A. L. R.; MONTEIRO, A. H. R.; SAITO, C. H. Contribuição da educação ambiental na explicitação e resolução de conflitos em torno dos recursos hídricos. Revista Ambiente e Educação, Rio Grande, v. 8, p. 117-129, 2003.

BUSTOS, M.R.L. A educação ambiental sob a ótica da gestão de recursos hídricos. São Paulo, 2003. Disponível em: < http://www.teses.usp.br/teses/disponiveis >. Acesso em 20 Mai 2019.

BRÜGGER, P. Educação ou Adestramento Ambiental?. Florianópolis: Letras contemporâneas, 1999.

CAMPOS, V. N. O.; FRACALANZA, A. P. Governança das águas no Brasil: conflitos pela apropriação da água e a busca da integração como consenso. Ambiente e Sociedade, Campinas, v. III, n. 2, p. 365-382, 2010.

CARVALHO, I. C. M. A invenção ecológica: sentidos e trajetórias da educação ambiental no Brasil. Porto Alegre, Editora da UFRS, 2ㅇ ed. 2002.

CÔRTES, P. L. Conception and development of a system used to organize and facilitate access to environmental information. JISTEM - Journal of Information Systems and Technology Management, vol.10, n.1, p.161-76, 2013.

GUIMARÃES, M. A Dimensão Ambiental Na Educação. Campinas: Papirus, 1995. 
JACOBI, P. R.; BARBI, F. Democracia e participação na gestão dos recursos hídricos no Brasil. Revista Katál, Florianópolis, v. 10, n. 2, p. 237-244, 2007.

LEFF. E. Saber Ambiental. Petrópolis: Vozes, 2001.

LEFF, E. Epistemologia Ambiental. 3 ed. São Paulo: Cortez, 2002.

LIMA, G.F. da C. Questão ambiental e educação: contribuições para o debate. Ambiente \& sociedade, n. 5, p. 135$153,1999$.

LOUREIRO, C. F. B. Problematizando conceitos: contribuições à práxis em educação ambiental. In: Pensamento complexo, dialética e educação ambiental. São Paulo: Cortez, 2006.

OLIVEIRA, V. M. B. O papel da Educação Ambiental na gestão dos recursos hídricos: Caso da Bacia do Lago Descoberto/DF. (Dissertação de Mestrado em Geografia). Brasília - DF: Instituto de Geociências da UnB, 2008.

PICCOLI, A. S.; KLIGERMAN, D. C.; COHEN, S. C.; ASSUMPÇÃO, R. F. A educação ambiental como estratégia de mobilização social para o enfrentamento da escassez de água. Ciência \& Saúde Coletiva, v. 21, n. 3, p. 797-808, 2016.

TOZONI- REIS, M. F. C. Educação Ambiental: natureza, razão e história. Campinas, SP. Autores associados, 2004.

TREVISOL, J.V.; FILIPINI, G. T. R.; DE CASSIA BARATIERI, R. A Educação Ambiental em Bacias Hidrográficas: uma experiência nas escolas públicas do Rio do Peixe (SC). Rev. eletrônica Mestr. Educ. Ambient. ISSN 1517-1256, v. especial, 2010.

TUNDISI, J.G. Recursos hídricos no futuro: Problemas e soluções. Estudos Avançados 22, 1- 16, 2008. 